\title{
Contribution of Veterinary Sector to Control COVID-19 Pandemic in Nepal
}

\author{
Anil Gautam ${ }^{1}$, Ashwani Khanal ${ }^{1}$, Deepak Subedi ${ }^{1,2^{*}}$, Suman Bhandari ${ }^{1}$, and Krishna Kaphle ${ }^{3}$ \\ ${ }^{I}$ Paklihawa Campus, Institute of Agriculture and Animal Science, Tribhuvan University, Sidharthanagar Municipality-1, Lumbini, Nepal \\ ${ }^{2}$ New Hope Agrobusiness Nepal Private Limited Nepal, Chitwan, Nepal \\ ${ }^{3}$ Associate Professor and Director, Veterinary Teaching Hospital, Paklihawa Campus, Institute of Agriculture and Animal Science, Tribhuvan \\ University, Sidharthanagar Municipality-1, Lumbini, Nepal \\ *Corresponding author's Email: subedideepu26@gmail.com; (DORCiD: 0000-0002-0677-7094
}

\begin{abstract}
Nepal has been identified in a high-risk zone by the World Health Organization (WHO) for the Corona Virus Disease of 2019 (COVID-19). Nepal's first official reported case was confirmed on 13 January 2020 and so far, 24,000 cases have tested positive with 91 deaths. The imposition of lockdown has begun since March 24 and it was extended until 22 July. Reverse transcriptase Polymerase Chain Reaction and rapid diagnostic tests are used by the Government of Nepal to identify COVID-19. Among the worst-hit sectors are tourism as well as travel and the farming industries, the later contributes to the employment of around $65 \%$ of the population and a significant share of the national economy. The loss of commercial sectors, such as dairy, feed, and poultry industries are estimated to be in billions of rupees. One shortcoming of resource poorly managed countries, such as Nepal is the lack of interdisciplinary coordination. Over half a decade long professional existence and crucial contributions in Nepal's overall development, veterinarians are just beginning to be recognized as essential service providers. Since veterinarians of Nepal have the experience of eradicating cattle plague dealing with Avian Influenza and Swine Flu among others, they study and seem to be mentally prepared to handle pandemics. Currently, five veterinary diseases diagnostic laboratories with RT-PCR facilities are serving as COVID-19 diagnosis labs. Veterinarians from Nepal are serving in innovating newer tools as well as performing, supervising, evaluating, reporting diagnosis, and actively in pursuit of establishing the One Health $(\mathrm{OH})$ approach. The sincere and patriotic role played by veterinarians has pressurized the government of Nepal to recognize veterinary service as an essential commodity. In this regard, universities should take the lead and bring veterinarians in policy and planning as well as decision making. The Tribhuvan University is responsible to have the initiative and Agriculture and Forestry University to deliver the missed opportunities. The 17 sustainable development goals that are to be achieved by 2030 are not possible without a multi-sectoral approach and veterinarians are best suited in this regard. It also needs to be realized that veterinarians are better positioned to handle emerging and re-emerging zoonotic diseases and capable of combating the present situation of COVID19 pandemics. Reiterating the fact that $\mathrm{OH}$ approach should not only be in paper and there is no alternative but combined utilization of scarce resources for healthy animals, humans, and the environment with the veterinary profession at its core.
\end{abstract}

Keywords: COVID-19, Essential services, One Health, SARS-CoV-2, Veterinary

\section{INTRODUCTION}

On 31 December 2019, a number of cases were reported to suffer from pneumonia with an unknown origin in Hubei Province, Wuhan, People's Republic of China (PRC) (Wang et al., 2020). World Health Organization (WHO) named it Corona Virus Disease of 2019 (COVID-19) on 11 February 2020. Alarm bells rang and this outbreak was declared as a public health emergency of international concern on 30 January and WHO waited until 11 March to announce it as a pandemic (Hau and Shaw, 2020). In this vein, severe acute respiratory syndrome coronavirus 2 (SARS-CoV-2) was an unprecedented agent that causes COVID-19 and is still under investigation. Similar to other pathogenic agents, it starts spreading from animals to humans and this animal-to-person spread was suspected after the initial outbreak in December among people who had a link to a large wet market in Wuhan, China. Victim "zero" is notably under serious investigation. Unless, WHO comes to a logical conclusion, the etiology for this unknown disease was identified as a novel type of coronavirus on 7 January, and the International Committee on Taxonomy of Viruses named it as SARSCoV-2 on 11 February (Singhal, 2020). The virus is changing dimension, evolving and rush for mass scale vaccine production or declare disease free status is becoming a tricky situation so is the effort to establish real origin of this microbe.

Regarding SARS-CoV-2, patients might be afflicted with symptoms, such as cough, shortness of breath or difficulty breathing, fever, chills, muscle pain, sore throat, and other less common symptoms (e.g., nausea, vomiting or diarrhea) during the first 2-14 days (Singhal, 2020). Currently, 216 countries and territories around the world have reported around 20.7 million positive cases and over 751 thousand fatalities among which the residents of the India, 
United States of America, Brazil, Spain, Italy, the United Kingdom, France are at high risks (WHO, 2020). According to the World Organization for Animal Health, the transmission of COVID-19 is mainly due to human-to-human contact and there is no evidence supporting the fact that animals are playing any significant epidemiological role in the disease transmission. Food and Agriculture Organization (FAO) also stated that animal products consumed mostly for food are safe to eat when they are well-cooked. According to recent studies which are few in number, there is a slight risk of COVID-19 transmission from animals to people but, it can still be transmitted from people to animals on some occasions. Among different types of animal species, dogs, cats, minks, and tigers have tested positive but there is not enough scientific evidence to identify the source of SARS-CoV-2 or to explain the original route of transmission to humans (Singhal, 2020).

Sad stories of people throwing away (killing) their pets for the fear of the virus and abandoning aged and diseased pets, as well as the pain and plight of the community animals, are heart-wrenching. Mink farms bred by the fur industry in Holland had to be shut down due to the fear of human infection to SARS-CoV-2 (Akhmetzhanov et al, 2020). Likewise, the governments of Canada and the United States locked down big commercial meat processing plants for the fear of the COVID-19 outbreak. Detection of virus in frozen food items is also being reported (Togoh, 2020), though the Beijing scare in June on imported salmons was brushed aside by WHO said that there is no evidence that the disease spreads by food or food products. On tracing the chopping board and faulty handling was blamed but that was after the shelves were emptied. Likewise, just recently Chinese city of Shenzhen raised the alarm bells again by announcing that chicken wings imported from Brazil tested positive for coronavirus (Gan, 2020). Though, it is unusual for salmons to carry the virus, chicken do suffer from corona virus inflicted disease called the infectious bronchitis disease (Poudel et al., 2020) but it is not the same as COVID-19.

Understanding the risk of human or animal exposure to the infected SARS-CoV-2 animals or their products is essential for preventing virus spread and prioritizing research in this field an urgent task. Protecting food systems, and preparation and adoption of the national $\mathrm{OH}$ investigations and mitigation measures equally important (El Masry et al., 2020). Boycotts, restricted transportation and trade of agriculture products citing COVID-19 precaution is another concern.

In Nepal, the first case of COVID-19 was reported on 13 January in a 32-year-old Nepalese student studying at Wuhan University of Technology, Wuhan, China (Bastola et al., 2020). As of 12 August, there were a total of 24,432 COVID-19 cases, out of whom 16728 were recovered and 91 were dead (MoHP, 2020). An epidemiological study estimated $2.25 \%$ prevalence and $0.5 \%$ case-fatality rate of COVID19 among the tested population in Nepal (Dhakal and Karki, 2020). Nepal has been on a nationwide lockdown since 24 March, it was then eased a bit but the lockdown was again extended until 22 July 2020. It is notable that Nepal evacuated its citizens residing in Wuhan on 15 February and had them quarantined for two weeks (Asim et al., 2020). The imposition of lockdown has a significant effect on various sectors in Nepal, especially the veterinary sector. As reported, organized commercial sectors, more specifically dairy, feed and poultry industries, have been hit hard and lost billions of local currencies. With this background in mind, the present article highlights the major impacts of COVID19 on the veterinary sector and suggestion on how it has to be given due role head for the agriculture-dependent economy of Nepal.

\section{Scenario of COVID-19 in Nepal}

Nepal is a landlocked country having an area of 147.181 square kilometers. It is bordered with China in the North (1,414 kilometers border with PRC's autonomous region of Tibet, in the Himalayas) and India on the other three sides. A revised map was issued amid threats of encroachment from two great nations, between which Nepal is sandwiched. The two most populous nations in China and India are emerging as hotbeds for virus spread which threatens Nepal with a high risk for the pandemic and also one of the least prepared (Dhakal, 2020). Quarantine facilities and intensive care units are getting crowded and this means that patients afflicted with COVID-19 have to wait long for empty beds (Poudel, 2020). At the time of manuscript revision on 12 August, there were a total of 24,432 cases with 16,728 recovery and 91 deaths (MoHP, 2020, Figure 1), but globally 161 Nepalese died due to COVID-19 (NRNA, 2020).

Returning migrants cause the surge of Covid-19 cases and keep the disease on an upward trend for some time. Remittance is the backbone of Nepal's economy and its sheer contribution to the financial situation of Nepal has been estimated $\$ 8.79$ billion in the fiscal year of 2018-2019 (MoLESS, 2020). For decades, India has been the largest destination for Nepalese immigrants, however, Middle East, Malaysia, South Korea, Japan, Europe, North America are also on the list (MoLESS, 2020, Figure 2). Among the Nepalese immigrants, a large number of people who returned from India continue to test positive, and accordingly faced severe hardship. The lockdown of over four months failed to prepare the country for the arrival and quarantine of the returnees in the border. Open border with India also proved to be disadvantageous as migrants (i.e., both Nepalese citizens and Indians) could easily sneak in and out from farmlands and river beds. Although public schools and other facilities were hastily used to house the migrants, the lack of sincere efforts and failure of resource mobilization were the major complaints from the majority. 
Given the global economic turmoil, it is likely that many of these migrants would stay in their home country since the appeal for their manual and semi-skilled type of labor gets dismissed or the job vacancies are filled with locals. There is no doubt that the lack of basic facilities in the hastily prepared makeshift camps, and government bogged down by surging cases is thinking beyond containing the spread. Waste management of these camps is a good example of how much we have learned from this pandemic and the concept of $\mathrm{OH}$. The excessive use of protective materials without any education for safe disposal using the three R's (Reduce, Reuse, and Recycle) is intriguing. Although there is a need for a structured change in waste management (i.e., both household and medical waste), Nepal's system of waste collection and safety have not moved beyond providing masks and latex gloves. Some changes, such as hand washing and social distancing, may have become a new normal, but again it is yet to be assessed if the pre, during, and post COVID-19 behavioral changes are significant.

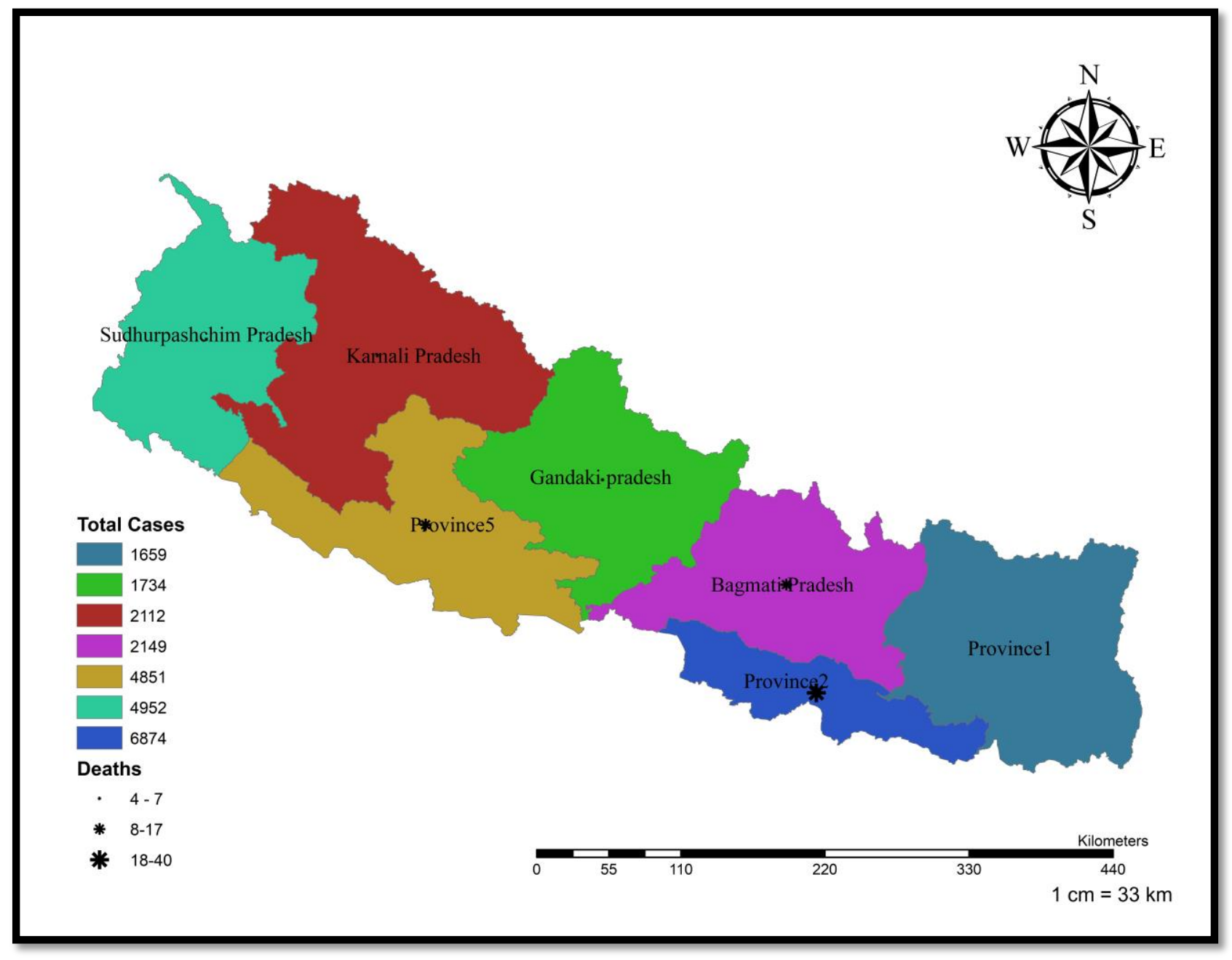

Figure 1. Provincial map of Nepal showing province wise COVID-19 cases and deaths on 10 June 2020. The high Himalayan regions have remained relatively safe while the south bordering India and cities close to the border have seen maximum cases.

\section{Veterinary medicine in the global scenario}

Tremendous efforts from multi-sectoral stakeholders are made to tackle the multifaceted viral pandemic. The frontline workers are risking their lives for the safety of their citizens and those in the background are busy working to find a solution to this current problem and likely new ones. Besides, the new experience of detecting and dealing with the novel coronavirus in animals and success in treatment and vaccination (Pedersen et al., 2019), veterinarians are also involved in the discovery of medicine and important immunological compounds. Various veterinary institutes in the USA and Australia are carrying out different research related to SARS-CoV-2 (Table 1). The experience of having managed threats for pandemics, such as avian Influenza (Horimoto and Kawaoka, 2001) and other crises have prepared veterinarians and veterinary laboratories to detect SARS-CoV-2 via reverse transcription polymerase chain reaction (RTPCR). Veterinarians are also providing personal protective equipment and ventilators to tackle with COVID-19. However, as real inside stories emerge from these diagnostic facilities veterinarians and veterinary technicians are given secondary roles and responsibilities. The planning of pandemic control, approach in community spread intervention have 
the most hearing from politicians, medical personals, administration and very little from veterinarians-which is not how it is supposed to be. Virus in community- its sewage system, its garbage bins or littered dumps now full of masks and snot, cough filled tissues, scavenging animals, interacting pets it is a complex cycle.

Table 1. The COVID-19 research activities undertaken by various veterinary institutes in the international arena

\begin{tabular}{|c|c|c|c|}
\hline $\mathbf{S N}$ & Research Activities & Working Institute & Reference \\
\hline 1 & $\begin{array}{l}\text { Developing a treatment protocol of Feline } \\
\text { Infectious Peritonitis in cats experimentally } \\
\text { infected with feline enteric coronavirus and } \\
\text { conducting clinical trials for the treatment of } \\
\text { COVI-19 }\end{array}$ & $\begin{array}{l}\text { University of California, Davis, School of } \\
\text { Veterinary Medicine }\end{array}$ & Pedersen et al. (2019) \\
\hline 2 & $\begin{array}{l}\text { Coronavirus testing, development of sample } \\
\text { diagnostic kits for SARS-CoV-2 and working for } \\
\text { the development of COVID-19 vaccine }\end{array}$ & $\begin{array}{l}\text { Louisiana State University, School of } \\
\text { Veterinary Medicine }\end{array}$ & LSU (2020) \\
\hline 3 & $\begin{array}{l}\text { Investigation on the SARS-CoV-2 spike protein } \\
\text { and mechanism for fusing with host cell which can } \\
\text { lead to vaccine and drug development }\end{array}$ & Cornell University of Veterinary Medicine & $\begin{array}{l}\text { Millet and Whittaker } \\
\text { (2014) }\end{array}$ \\
\hline 4 & $\begin{array}{l}\text { Research for treatment of COVID-19 using } \\
\text { Ivermectin. (Parasiticide, used in veterinary } \\
\text { medicine). Ivermectin impedes SARS-CoV-2 in } \\
\text { vitro }\end{array}$ & $\begin{array}{l}\text { Victorian Infectious Diseases Reference } \\
\text { Laboratory, Royal Melbourne Hospital, The } \\
\text { Peter Doherty Institute for Infection and } \\
\text { Immunity }\end{array}$ & Caly et al. (2020) \\
\hline
\end{tabular}

\section{Veterinary sector in Nepal}

Veterinary is an important profession in Nepal with around 65\% population engaged in agriculture. The mass immigrant returnees are deemed to livestock agriculture as their main occupation for survival. The livestock sector along with fisheries contribute to $12.5 \%$ of the national total Gross Domestic Product (GDP) and the poultry sector counts for 4\% GDP (FAO, 2014). Agriculture as a whole has been a hard-hit sector, and poultry as the most organized sector has incurred a daily loss above Rs 220 million due to the lockdown in the country (Dhungana, 2020). With a network of 10 veterinary laboratories, 48 veterinary hospitals, 753 animal service centers, and other private animal hospitals and clinics in Nepal, most had to close down due to the imposition of lockdown. The lockdown in Nepal has a detrimental effect on all sectors, especially dairy, egg, and meat sectors where a large number of multiple species were under husbandry practice (Table 2, Krishi Dairy, 2019).

Table 2. Nepal's diverse species both in the wilderness and in husbandry practices

\begin{tabular}{lccc}
\hline Domestic Ruminants & Number & Other Animals & Number \\
\hline Cattle & 7376306 & Pig & 1435369 \\
Buffalo & 5277819 & Chicken & 72245732 \\
Sheep & 800749 & Duck & 404670 \\
Goat & 11647319 & Rabbit & 75740 \\
Yak/Chauri & 69978 & Horse & 58091 \\
\hline
\end{tabular}

Except for some selected veterinary hospitals (e.g., the central veterinary hospital, some district-level veterinary hospitals, and expert centers), Veterinary Teaching Hospital of the Institute of Agriculture and Animal Science as well as Tribhuvan University of Nepal were open to provide their services. The Nepal Veterinary Association (NVA) tried to set up telemedicine centers and requested the help of charities to feed community animals that were left starving. Likewise, one notable achievement of NVA during this lockdown was to obtain an interim verdict (on 6 May 2020) from the Supreme Court of Nepal to the GoN to enlist veterinary services as an essential service. On World Veterinary Day 2020, NVA organized a webinar with the purpose of global public awareness towards COVID-19 situation with the major focus of Nepal on three different topics, a) development of COVID-19 vaccine, b) medical aspects of COVID-19, inter sectoral collaboration, and COVID-19 epidemiology with a global focus, and c) the regional and national scenario of COVID-19. Difficulties faced by veterinarians to deliver their services due to blanket lockdown was also realized by NVA and the strong leadership said enough of it. After two months of lockdown, on 21 May, the Supreme Court of 
Nepal ordered GoN enlisted veterinary services as an essential sector which allows veterinarians to carry out their work during lockdown and other administration restrictions (My Republica, 2020).

There is no doubt that we have no other options but to evolve together with these emerging and reemerging diseases. The effects of global politics and insecurity over the pandemics, its economics, trade barriers and restrictions will be remain for long time (Sanford et al., 2016). In this regard, New Zealand, Hong Kong are ideal example that we can never say that we have contained the virus, hence $\mathrm{OH}$ approach intended mitigating it in collective community changes in behavior is an envisioned approach for the future (Kaphle, 2020). Even in this crisis, veterinary diagnostic facilities that are playing important roles in combating COVID-19 still have areas to work upon beyond routine protocol screening. Overwhelmed and stretched resources are obvious but veterinarians can be pooled for beyond lab works too. In Nepal, five well equipped veterinary laboratories are supporting the government's testing of COVID-19 (MoHP, 2020, Figure 3). This disease has a negative effect not only on peoples' lives but also on stray animals. Due to the closure of butcher shops and restaurants, as well as low waste scavenging, approximately 26,000 street dogs in Kathmandu and much more in the country are starving and no effective steps have been taken by the GoN (Ojha and Lama, 2020). However, various animal welfare organizations, such as Sneha's Care, Animal Nepal, and Kathmandu Animal Treatment Centre, Street Animal Welfare (SAW) and volunteer individuals have taken the responsibility to feed community animals, including dogs, cattle, monkeys on daily basis (Ojha and Lama, 2020).This situation is due to the lack of a separate government body and institutional framework for the enactment of $\mathrm{OH}$ approach in Nepal (Acharya et al., 2019).

The $\mathrm{OH}$ is an approach for designing and implementing programs, policies, legislation, and research in which multiple sectors involved in public health, animal health, and eco-system-related health issues communicate and work together to achieve better public health outcomes (Acharya et al., 2019; Poudel et al., 2020; figure 4). In such a catastrophic situation of COVID-19 where there is no vaccination and treatment, $\mathrm{OH}$ approach is necessary to stand against this disease, and in nations with poor health facilities, such as Nepal, the government should put more emphasis on such approaches (Acharya et al. 2019). Although, several action steps, including nationwide lockdown, restriction of foreigners, practice of isolation, and quarantine, and sample test by rapid diagnostic test and RT-PCR are done by the government to control the pandemic COVID-19 after around three months of lockdown, there are less than 1500 PCR tests per day which are insignificant in the present context. In this situation, GoN and MoHP are unable to fully utilize the veterinary sector resources which could be an effective way to increase sample testing of COVID-19. The optimum utilization of manpower related to the medical and veterinary field, increase in the number of RT-PCR tests. The people following preventive measures can help to combat COVID-19. GoN should realize the importance of the veterinary sector and implement the $\mathrm{OH}$ approach effectively to win the battle against COVID-19 in Nepal.

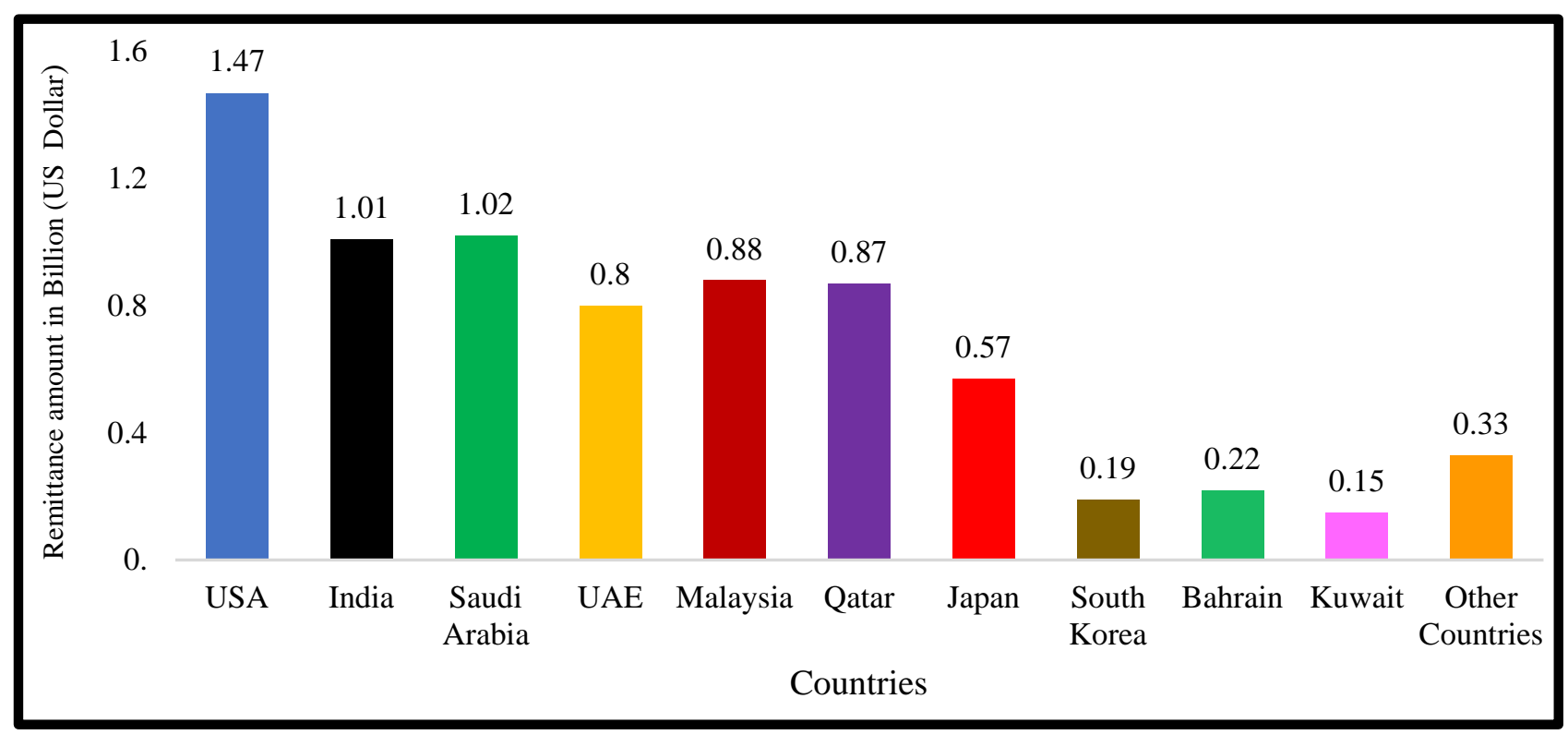

Figure 2. Remittance is the backbone of Nepal's economy. The current global recession is bound to hit Nepal hard and the return of Nepalese from abroad is both a challenge and an opportunity to kick start productivity in the country. Hardworking, patriotic, and now more experienced foreign countries returned migrants are likely to be a huge asset if the government's policy and plan can engage them in productive sectors. Bar graph showing remittance by destination in 2017-18. 


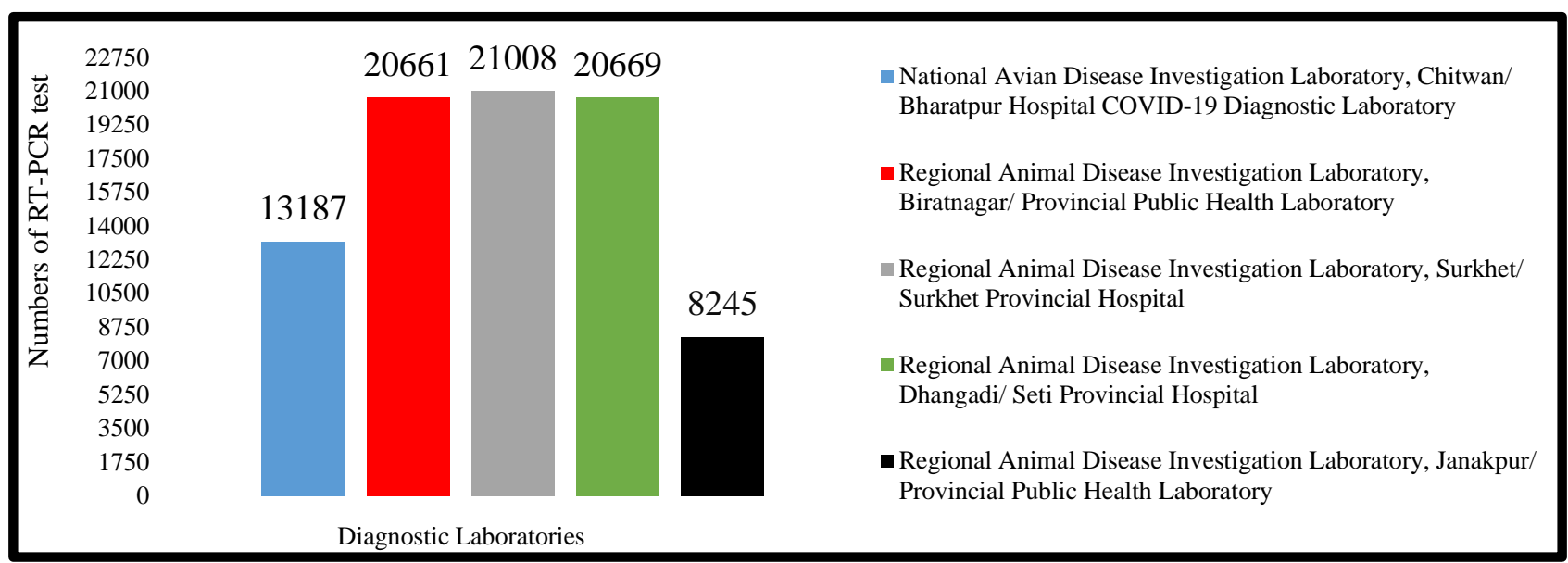

Figure 3. Bar graph showing the total number of reverse transcription-polymerase chain reaction tests of COVID-19 conducted in veterinary laboratories of Nepal on 12 August 2020.

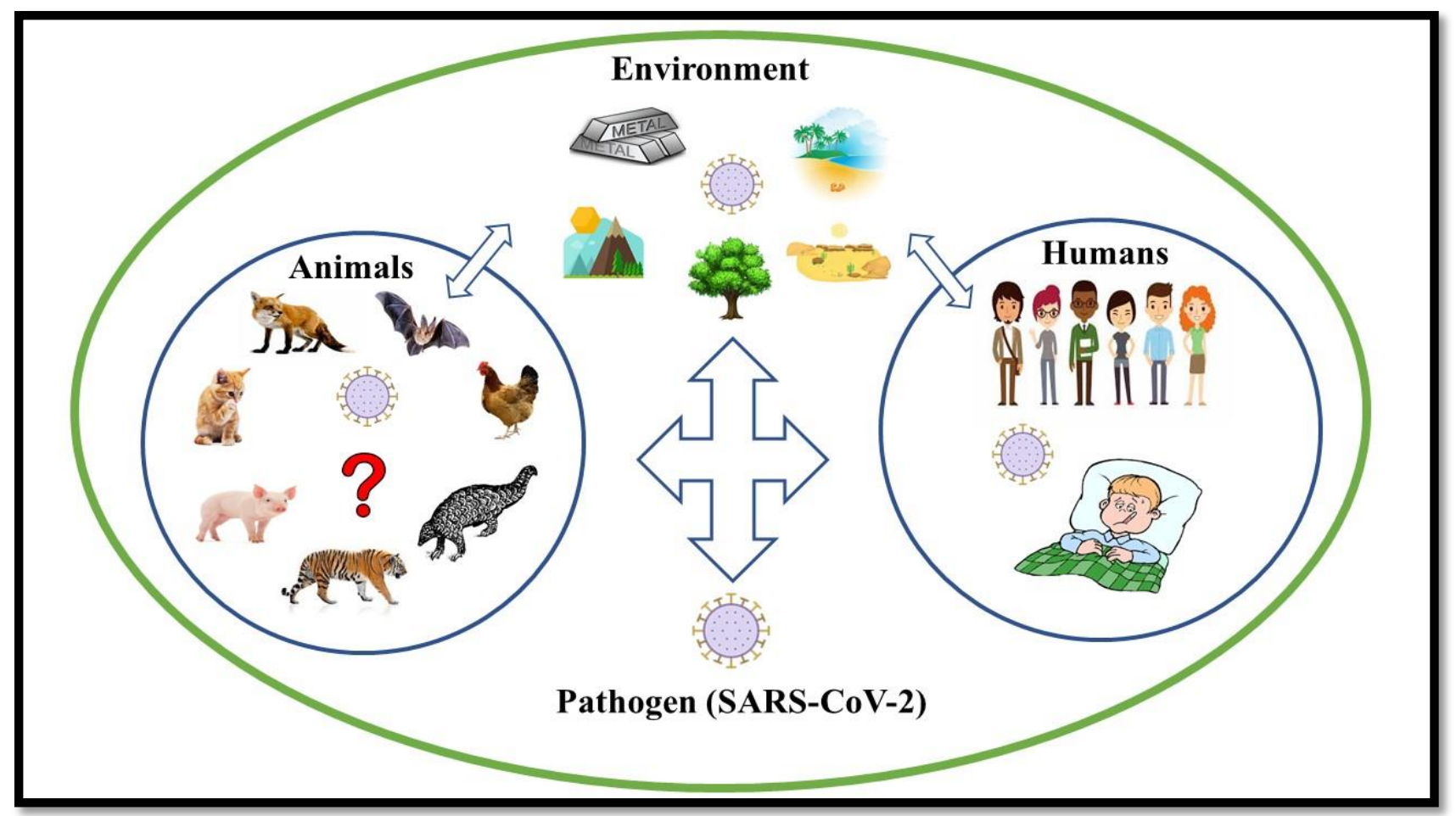

Figure 4. Interrelation of animals, humans, environment, and pathogen in the context of COVID-19

\section{CONCLUSION}

Across the world, there is debate on whether lockdown is going to continue or life returns to its normal form. Political affiliations, as well as ethnic and geographical dimensions, are dissected over how one is perceiving the threat and its handling by their respective governments. Even satirical bibliography has emerged in response to comments by the politicians and health officials at national and international levels-vodka or spice as prevention approach. The COVID-19 is rapidly spreading throughout the country and massively affecting the daily life of human beings. In case the government ignores the veterinary services as an essential sector, it may face economic and animal health challenges. Although avian and animal disease laboratories conduct the diagnostic test of SARS-CoV-2, there still is a long way to go for an effective health approach in Nepal. Veterinarians can play a crucial role in controlling such emergencies, however, there is no alternative for $\mathrm{OH}$ and one world approach. Conservationists alarmed that the coronavirus pandemic could spark a surge in ocean pollution-adding to a gloomy situation of plastic waste that already threatens marine life. Coronavirus waste, such as disposable protective materials and latex gloves can be seen littered along roadside and streams ending up floating like jellyfish across sea beds. Safely managing medical and domestic waste is crucial to successfully containing the disease and as drainage gets clogged, community animals ingest or play around with them we are inviting trouble. Plastic recovery from bellies of community cows that is the national animal of Nepal is frequently 
reported in kilograms and it looks like field veterinarians have added risk to deal with. We have not learnt from the past and this unsustainable COVID-19 waste management is bound to hurt the achievement of sustainable development goals by 2030 (You et al., 2020). There is no doubt that lockdown and minimized human activities could have a positive impact on the environment. This pandemic has led to environmental benefits, such as cleaner air, lower carbon emissions, and respite for wildlife. Reduced human mobility during the pandemic can reveal critical aspects of our impact on animals and provide important guidance on how to share space on this crowded planet (Christian et al., 2020). As vaccine development rush continues, some already declared (Figure 5), the traffic is getting crowded. Remarkable progress has been made in the process of COVID-19 vaccine development with the human trials stage achieved just 67 days after the outbreak. The WHO report on status of the vaccine development process is encouraging (Figure 6, Mackintosh et al., 2020). Once rich nations vaccinate their citizens, poorer countries may receive it as grants or may be reversed to establish safety and completion of phase 3. However, we as veterinarians will have roles in making sure the vaccines have no spillover effects in animals and vice versa. Now, the question is whether we can capitalize on this momentum and achieve collective community led transformation? Veterinarians and the veterinary sector in Nepal like those of other countries are hard hit by this COVID-19 pandemic and yes, they are integral part of the economy recovery and community healing strategies. The frontline warriors are working tirelessly and under no spotlight. With an established multi-sectoral roles and responsibilities, the reseahcers have to reformulate policies for achieving sustainable development goals by 2030 . Nepalese veterinarians are aware and very much ready, but is the government even thinking in that direction is the big question.

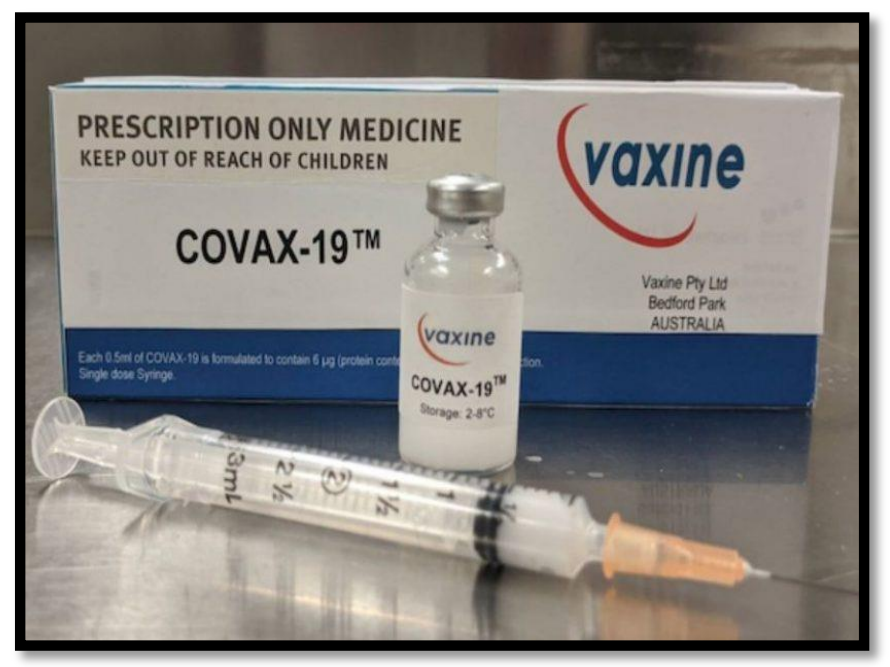

Figure 5. Discovery of the vaccine for COVID-19, many nations have declared that they have successfully tested the vaccine and ready for mass production. This advertisement is one such example from Australian company. Some multi-billionaires were already ahead of the game and preparing facilities in the anticipation of a possible pandemic. Nations and institutions were also on their mark as people currently see the announcement about the success of certain stages in the production process. There are also claims about sabotage, espionage, and signs of healthy and unhealthy competitions. This vaccine is reported in news to be leading the race but it faces stiff competition.

ONW Covid-19 vaccine

\section{Stage of vaccine development}

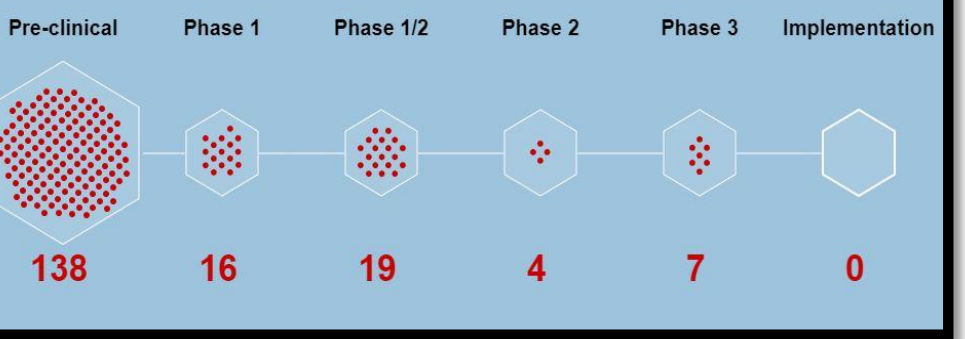

Figure 6. Multi billion dollars are spent by nations, universities, foundations, multinational companies among other players. The race to be the first to develop is seen with Russia, China, Australia, India rushing ahead, though blame of cutting corners and ignoring safety standards is also making news (Whatever, the figure retrieved from $\mathrm{CNN}$ shows that there is a healthy pool of interest and investment and some already close to the implementation stage).

\section{DECLARATIONS}

\section{Author's contribution}

Deepak Subedi conceptualized the study. Deepak Subedi, Anil Gautam, Ashwani Khanal, and Suman Bhandari wrote the manuscript. Deepak Subedi and Krishna Kaphle reviewed and edited the manuscript. All authors read and approved the final manuscript. 


\section{Competing interests}

The authors declare no conflict of interest.

\section{Acknowledgments}

To all frontline workers in the challenge against the pandemic COVID-19.

\section{REFERENCES}

Acharya KP, Karki S, Shrestha K and Kaphle K (2019). One health approach in Nepal: Scope, opportunities and challenges. One Health, 8, 100101. DOI: https://doi.org/10.1016/j.onehlt.2019.100101

Akhmetzhanov AR, Linton NM and Nishiura H (2020). Rising evidence of COVID-19 transmission potential to and between animals: do we need to be concerned? medRxiv. DOI: https://doi.org/10.1101/2020.05.21.20109041

Asim M, Sathian B, Van Teijlingen E, Mekkodathil A, Subramanya SH and Simkhada P (2020). COVID-19 pandemic: Public health implications in Nepal. Nepal Journal of Epidemiology, 10(1): 817-820. DOI: https://dx.doi.org/10.3126\%2Fnje.v10i1.28269

Bastola A, Sah R, Rodriguez-Morales AJ, Lal BK, Jha R, Ojha HC, Shrestha B, Chu DK, Poon LL, Costello A and Morita K (2020). The first 2019 novel coronavirus case in Nepal. The Lancet Infectious Diseases, 20(3): 279-280. DOI: https://doi.org/10.1016/S1473-3099(20)30067-0

Caly L, Druce JD, Catton MG, Jans DA and Wagstaff KM (2020). The FDA-approved drug ivermectin inhibits the replication of SARS-CoV-2 in vitro. Antiviral research, 104787. DOI: https://doi.org/10.1016/j.antiviral.2020.104787

Christian R, Matthias-Claudio L, Amanda EB, Sarah CD, Carlos MD, Walter J, Mark J, Akiko K, Roland K, Thomas M et al. (2020). COVID-19 Lockdown Allows Researchers to Quantify the Effects of Human Activity on Wildlife. Nature ecology \& evolution. DOI: https://doi.org/10.1038/s41559-020-1237-z

Dhakal S and Karki S (2020) Early Epidemiological Features of COVID-19 in Nepal and Public Health Response. Frontiers in Medicine. 7:524. DOI: https://doi.org/10.3389/fmed.2020.00524

Dhakal S (2020). The Himalayan Times, Nepal ill-prepared for coronavirus outbreak. Available at: https://thehimalayantimes.com/nepal/nepal-ill-prepared-for-coronavirus-outbreak/

Dhungana B (2020). My Republica, Poultry sector bears loss from lockdown. Available at: https://myrepublica.nagariknetwork.com/news/poultry-sector-bears-loss-from-lockdown/

El Masry I, von Dobschuetz S, Plee L, Larfaoui F, Yang Z, Song J, Pfeiffer D, Calvin S, Roberts H, Lorusso A et al. (2020). Exposure of humans or animals to SARS-CoV-2 from wild, livestock, companion and aquatic animals: Qualitative exposure assessment. FAO animal production and health, Paper 181. Rome, FAO. DOI: https://doi.org/10.4060/ca9959en

Food and Agriculture Organization (FAO) (2014). Poultry Sector, Nepal. Available at: http://www.fao.org/3/a-i3964e.pdf

Gan N (2020). CNN. Chicken wings test positive for Covid-19 in China, but there's no evidence of food transmission, experts say. Available at: https://edition.cnn.com/2020/08/13/asia/china-coronavirus-chicken-wings-intl-hnk/index.html

Horimoto T and Kawaoka Y (2001). Pandemic threat posed by avian influenza A viruses. Clinical microbiology reviews, 14(1): 129149. DOI: https://doi.org/10.1128/CMR.14.1.129-149.2001

Hua J and Shaw R (2020). Corona virus (Covid-19) "infodemic" and emerging issues through a data lens: The case of china. International journal of environmental research and public health, 17:7: 2309. DOI: https://doi.org/10.3390/ijerph17072309

Kaphle K (2020). Veterinary medicine as the core of the one health approach for Nepal's preparedness to pandemics like COVID19. Applied Science and Technology Annals. 1 (1), 122-130.

Krishi Dairy, Government of Nepal, Ministry of Agriculture and Livestock Development (2019). Available at: https://zonedhankuta.pmamp.gov.np/tabs/krishi-diary-2076/

Louisiana State University (LSU) (2020). LSU Coronavirus Testing Lab Supports 18 Louisiana Medical Facilities. Available at: https://www.lsu.edu/research/news/2020/0404-riverroadtestinglab.php

Mackintosh E, Mezzofio G and Polglase K (2020). CNN. Inside the multibillion dollar race for a Covid-19 vaccine. Available at: https://edition.cnn.com/interactive/2020/08/health/coronavirus-vaccine-race-intl/

Millet JK and Whittaker GR (2014). Host cell entry of Middle East respiratory syndrome coronavirus after two-step, furin-mediated activation of the spike protein. Proceedings of the National Academy of Sciences, 111(42): 15214-15219. DOI: https://doi.org/10.1073/pnas.1407087111

Ministry of Health and Population (MoHP) (2020). Available at: https://covid19.mohp.gov.np

Ministry of Labour, Employment and Social Security (MoLESS), Government of Nepal, Labour Migration Report (2020). Available at: https://moless.gov.np/wp-content/uploads/2020/03/Migration-Report-2020-English.pdf

Mishra A (2020). The existing laboratory was not used. Kantipur. Available at: https://ekantipur.com/news/2020/04/10/158648639610733697.html

My Republica, Supreme Court directs govt to include veterinary service under "essential services" (2020). Available at: https://myrepublica.nagariknetwork.com/news/supreme-court-directs-govt-to-include-veterinary-service-under-essentialservices/

Non-Resident Nepali Association (NRNA) (2020). Available at: https://www.nrna.org/News/newsid/1673

Ojha and Lama TN (2020). It's not just humans suffering under the lockdown - dogs are, too. The Kathmandu Post. Available at: https://tkpo.st/2WLHdgU 
Pedersen NC, Perron M, Bannasch M, Montgomery E, Murakami E, Liepnieks M and Liu H (2019). Efficacy and safety of the nucleoside analog GS-441524 for treatment of cats with naturally occurring feline infectious peritonitis. Journal of feline medicine and surgery, 21(4): 271-281. DOI: https://doi.org/10.1177\%2F1098612X19825701

Poudel A (2020). The Kathmandu Post, Nepal's hospitals have no ICUs to treat coronavirus patients, doctors say. Available at: https://tkpo.st/2Sk9A3i

Poudel U, Subedi D, Pantha S and Dhakal S (2020). Animal coronaviruses and coronavirus disease 2019: Lesson for One Health approach. Open Veterinary Journal, 10(3): 239-251. DOI: http://dx.doi.org/10.4314/ovj.v10i3.1

Sanford S, Pelzer J and McDonough P (2016). Preparedness as a technology of (in) security: Pandemic influenza planning and the global biopolitics of emerging infectious disease. Social Theory \& Health, 14(1): 18-43. DOI: https://dx.doi.org/10.1057\%2Fsth.2015.8

Singhal TA (2020). Review of Coronavirus Disease-2019 (COVID-19). The Indian Journal of Pediatrics, 87: 281-286. DOI: https://doi.org/10.1007/s12098-020-03263-6

Togoh I (2020). Forbes. Coronavirus Detected on Chicken Wings Imported from Brazil, Chinese Officials Say. Available at: https://edition.cnn.com/2020/08/13/asia/china-coronavirus-chicken-wings-intl-hnk/index.html

Wang C, Horby PW, Hayden FG and Gao GF (2020). A novel coronavirus outbreak of global health concern. The Lancet, 395, 70473. DOI: https://doi.org/10.1016/S0140-6736(20)30185-9

World Health Organisation (WHO) (2020). Coronavirus disease (COVID-19) pandemic, 2020. Available at: https://www.who.int/emergencies/diseases/novel-coronavirus-2019

You S, Sonne C and Ok YS (2020). COVID-19's unsustainable waste management. Science, 368(6498): 1438. DOI: http://doi.org/10.1126/science.abc7778 